\title{
Fanconi Syndrome Induced by Tenofovir in a Diabetic Patient with a History of Chronic Hepatitis B: A Case Report
}

\author{
Zeinab Saremi ${ }^{1}$, Tahereh Fakharian ${ }^{2, *}$
}

1. Department of Rheumatology, Faculty of Medicine, Birjand University of Medical Sciences, Birjand, Iran

2. Department of Gastroenterology and Hepatology, Faculty of Medicine, Birjand University of Medical Sciences, Birjand, Iran

\footnotetext{
* Corresponding Author:

Tahereh Fakharian, MD

Department of Gastroenterology \&

Hepatology, Faculty of Medicine,Birjand University of Medical Sciences, Birjand, Iran
}

Tel: +985632041100

Fax: + 985632214307

Email: t.fakharian@gmail.com

Received : 20 Oct. 2020

Accepted : 04 Apr. 2021

\section{ABSTRACT}

Tenofovir disoproxil fumarate is a nucleotide reverse transcriptase inhibitor and has been extensively used in the first-line treatment of viral infectious diseases such as chronic hepatitis B. Despite its good safety, the development of Fanconi syndrome is a rare adverse effect of long-term tenofovir therapy. Here, we report a case of a 62 -year-old diabetic woman with a history of chronic hepatitis B who was exposed to tenofovir and developed drug-associated Fanconi syndrome. After discounting tenofovir, the patient's bone pain was markedly reduced.

\section{KEYWORDS:}

Fanconi Syndrome; Tenofovir; Diabetic Patient; Chronic Hepatitis B

Please cite this paper as:

Saremi Z, Fakharian T. Fanconi Syndrome Induced by Tenofovir in a Diabetic Patient with a History of Chronic Hepatitis B: A Case Report. Middle East J Dig Dis 2021;13: 374-377. doi: 10.34172/mejdd.2021.250.

\section{INTRODUCTION}

Tenofovir disoproxil fumarate is one of the most widely used antiviral agents in treating viral infections such as chronic hepatitis B and human immunodeficiency virus (HIV). It has good safety, tolerability profiles, and favorable efficacy. ${ }^{1}$ Despite its safety and clinical efficacy, long-term tenofovir therapy has been shown to be related to an uncommon adverse reaction like development of Fanconi syndrome. ${ }^{1}$ Clinical manifestations of Fanconi syndrome include osteomalacia, polydipsia, polyuria, and dehydration. ${ }^{2}$ Here, we report a case of tenofovir-induced Fanconi syndrome in a diabetic patient with a history of chronic hepatitis B.

\section{CASE REPORT}

A 62-year-old woman with diabetes and a history of chronic hepatitis B was referred to our rheumatology unit in 2018 because of severe bone pain. The patient's pain started 2 years earlier, and during this time, the pain intensity increased. Because of the severe bone pain, she could not stand. Meanwhile, she had night pains, and recently she had an orthopedic cast for 2 weeks due to a leg fracture. At that time, initial clinical examinations for 

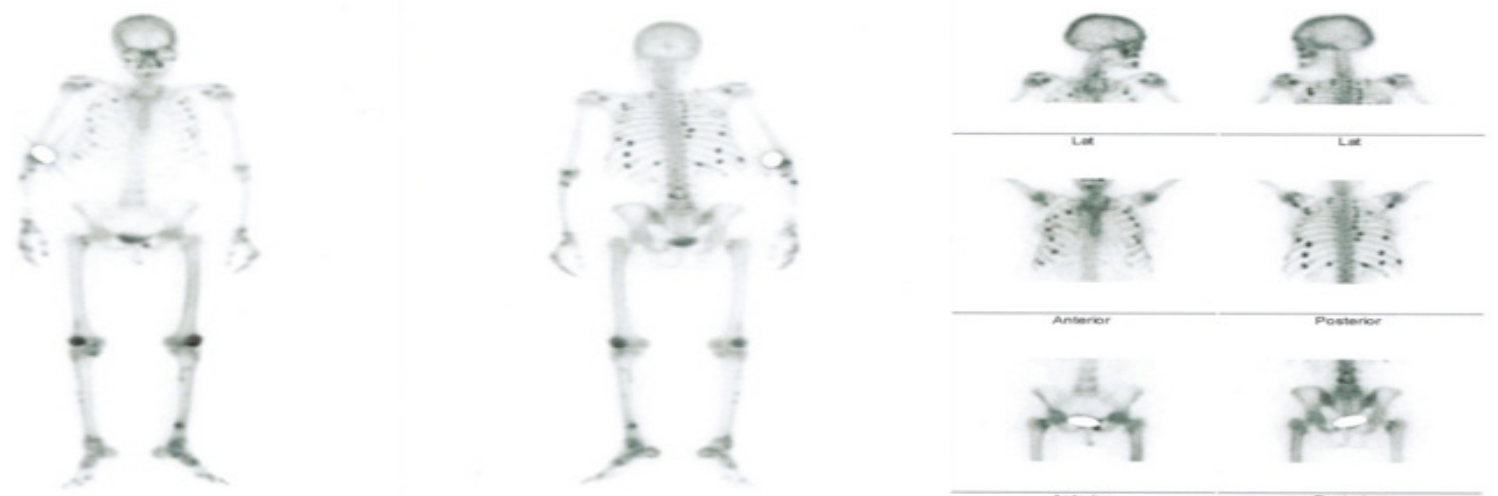

Fig.1: Whole-body bone scan in a patient with osteomalacia. Increased tracer uptake in the bilateral ribs, inferior rami of pubic bone on the left side, lumbar vertebra, and proximal portion of the bilateral tibia and fibula, distal part of the left tibia and mid part of the right leg. The bone scan also showed irregular increased tracer uptake in the knees. Multiple bone fractures were observed.

bone symptoms were performed, and no evidence was found. Antiviral therapy was started in 2005. Medications were as follows: Tenofovir (300 mg/day), aspart, and glargine insulin. Vital signs were normal, blood pressure (BP) was 130/80 $\mathrm{mm} \mathrm{Hg}$, and heart rate (HR) was 67 beats/min. Axillary temperature was $37^{\circ} \mathrm{C}$. No joint involvement could be detected. Thyroid examinations were normal. No peripheral lymphadenopathy was detected. Neurological findings were normal.

At that time, laboratory results were as follow: i) there was a clear trend of increase in alkaline phosphatase (ALP) level (720 IU/L in 2019 that recently had reached 1738 and $2340 \mathrm{IU} / \mathrm{L})$, ii) the patient's parathyroid hormone $(\mathrm{PTH})$ was normal, iii) serum calcium concentration was $9.6 \mathrm{mg} / \mathrm{dL}$, serum phosphate level at several times was $2 \mathrm{mg} / \mathrm{dL}$ and $1 / 2 \mathrm{mg} / \mathrm{dL}$ (range 2.5 4.5), serum sodium and potassium levels were $138 \mathrm{mEq} / \mathrm{L}$ and $4 \mathrm{mEq} / \mathrm{L}$, respectively, creatinine was $2 \mathrm{mg} / \mathrm{dL}$.

In further laboratory investigations, bicarbonate $\left(\mathrm{HCO}_{3}\right)$ was $20 \mathrm{mEq} / \mathrm{L}, \mathrm{pH}$ (7.32), and $\mathrm{PCO}_{2}$ (47 $\mathrm{mmHg}$ ) indicated metabolic acidosis. Other laboratory results were as follow: i) aspartate transferase (AST) and alanine transferase (ALT) was $21 \mathrm{IU} / \mathrm{L}$ and 14 IU/L, respectively,) The 25-OH-calciferol level was $54 \mathrm{ng} / \mathrm{mL}$, Gamma-glutamyl transferase (GGT) was normal, iii) serum protein electrophoresis was normal, iiii) erythrocyte sedimentation rate (ESR) was $3 \mathrm{~mm} / \mathrm{hr}$, fasting blood sugar (FBS), and HbA1C were $98 \mathrm{mg} / \mathrm{dL}$ and $7.3 \%$, respectively, but glucose and protein were seen in the urine.

With regards to the low serum phosphate, normogly- cemic glycosuria, and proteinuria, 24-hour urine examination was requested to evaluate tenofovir-associated Fanconi syndrome. The urinary phosphate and protein was $180 \mathrm{mg} /$ day (normal range: $<100 \mathrm{mg}$ /day) and 670 $\mathrm{mg} /$ day, respectively.

Bone scintigraphy showed increased uptake in the ribs on both sides, the lumbar spine, and proximal tibia and fibula, suggesting hyperparathyroidism (figure 1). Bone densitometry revealed severe osteoporosis (spine T score: -4.6 and pelvis $\mathrm{T}$ score -5.2 ). All secondary causes of severe osteoporosis had been ruled out.

Considering the clinical course of symptoms including recurrent bone fractures in the last 2 years, normoglycemic glycosuria, proteinuria, hypophosphatemia, and phosphaturia, tenofovir-associated Fanconi syndrome was diagnosed. Tenofovir (300 mg/day) was discontinued and replaced with tenofovir alafenamide (TAF) (25 mg/day). Moreover, oral phosphate and calcium were given to the patient. After 2 months, the patient returned to our clinic while her pain was markedly reduced, and she was able to stand. Because of severe osteoporosis, denosumab was prescribed. In the next visit, a 24-hour urine exam was requested, and results were as follows: i) serum calcium and phosphate concentration were $9.5 \mathrm{mg} / \mathrm{dL}$ and $4.5 \mathrm{mg} / \mathrm{dL}$, respectively, and ii) urine protein decreased to $210 \mathrm{mg}$ /day.

\section{DISCUSSION}

The current study presented a case of tenofovirinduced Fanconi syndrome in a 62-year-old diabetic patient with a history of chronic hepatitis B. Clinical, 
and biological characteristics of our patient are similar to those patients with hepatitis B diagnosed with tenofovir-related Fanconi syndrome. ${ }^{3,4}$ Several risk factors were identified for the development of Fanconi syndrome, including patient's age, sex, antiviral therapies, hypertension, and diabetes. ${ }^{4}$

Impairment of the proximal tubule reabsorption is one of the main characteristics of Fanconi syndrome, which causes normoglycemic glycosuria, proteinuria, hypophosphatemia, phosphaturia, hypouricemia, and type II renal tubular acidosis. ${ }^{5}$

In the present study, our patient was diagnosed with hypophosphatemic osteoporosis and osteomalacia secondary to tenofovir-induced Fanconi syndrome. Osteoporosis and osteomalacia could affect bone structure via several important mechanisms, including reduction of bone density and impairment of mineralization. ${ }^{6,7}$ Interestingly, clinical manifestations of osteoporosis and osteomalacia are distinguishable. In osteomalacia, bone pain and muscle weakness are more common than in osteoporosis. ${ }^{7,8}$ Previous research reports have been demonstrated bone density reduction in patients under tenofovir therapy. ${ }^{9,10}$ Moreover, in several toxicology studies, reversible hypophosphatemia and osteomalacia were shown following tenofovir therapy. ${ }^{11}$ In this regard, underlying mechanisms by which tenofovir induced bone loss have been described. Tenofovir by inducing proximal tubule dysfunction and Fanconi syndrome, leads to renal phosphate wasting and subsequent bone demineralization. ${ }^{9,10}$ Moreover, tenofovir increased bone loss by altering the expression of several important genes in osteoblasts and osteoclasts and also by interfering with the balance between bone resorption and formation play crucial roles in developing osteomalacia. ${ }^{9,10}$ In the clinical manifestation of our patient, a reduction in the bone density and also recurrent bone fractures was seen, suggesting osteomalacia and severe osteoporosis secondary to the tenofovir-induced Fanconi syndrome, which is in accordance with findings of the previous studies. ${ }^{5,12}$ Our patient had received tenofovir at a daily dose of $300 \mathrm{mg}$. After diagnosing Fanconi syndrome related to tenofovir, tenofovir was discontinued and replaced with TAF at a daily dose of $25 \mathrm{mg}$. TAF is a new formulation of tenofovir that has been approved for treating HBV and HIV with lower nephrotoxicity. ${ }^{13}$ Moreover, for 2 months, phosphate and calcium with high doses were given to the patient, and then osteoporosis therapy was started by administering denosumab. Following these therapies, the patient's bone pain was significantly attenuated, and she was able to stand.

\section{CONCLUSION}

Taken together, the current case report suggests that tenofovir can induce osteoporosis, osteomalacia, and renal and tubular dysfunctions. Therefore, close monitoring of patients receiving tenofovir with several simple tests for evaluating phosphaturia, phosphoremia, proteinuria, glycosuria, electrolytes, and serum creatinine is recommended

\section{ETHICAL APPROVAL}

There is nothing to be declared.

\section{CONFLICT OF INTEREST}

The authors declare no conflict of interest related to this work.

\section{REFERENCES}

1. Luni FK, Khan AR, Prashar R, Vetteth S, Duggan JM. Fanconi Syndrome and Antiretrovirals: It Is Never Too Late. Am J Ther 2016;23:e558-60. doi. org/10.1097/MJT.0000000000000095

2. Foreman JW. Fanconi Syndrome. Pediatr Clin North Am 2019;66:159-67. doi.org/10.1016/j.pcl.2018.09.002

3. Gracey DM, Snelling P, McKenzie P, Strasser SI. Tenofovir-associated Fanconi syndrome in patients with chronic hepatitis B monoinfection. Antivir Ther. 2013;18:945-8. doi.org/10.3851/imp2649

4. Viganò M, Brocchieri A, Spinetti A, Zaltron S, Mangia G, Facchetti F, et al. Tenofovir-induced Fanconi syndrome in chronic hepatitis B monoinfected patients that reverted after tenofovir withdrawal. $J$ Clin Virol. 2014;61:600-3. doi: 10.1016/j.jcv.2014.09.016.

5. Chung TL, Chen NC, Chen CL. Severe hypophosphatemia induced by denosumab in a patient with osteomalacia and tenofovir disoproxil fumaraterelated acquired Fanconi syndrome. Osteoporos Int 2019;30:519-523. doi: 10.1007/s00198-018-4679-2.

6. Taxel P, Kenny A. Differential diagnosis and secondary causes of osteoporosis. Clin Cornerstone 2000;2:1121. doi: 10.1016/s1098-3597(00)90002-4. 
7. Babayev R, Nickolas TL. Bone Disorders in Chronic Kidney Disease: An Update in Diagnosis and Management. Semin Dial 2015;28:645-53. doi: 10.1111/ sdi. 12423.

8. Francis RM, Selby PL. Osteomalacia. Baillieres Clin Endocrinol Metab 1997;11:145-63. doi: 10.1016/ s0950-351x(97)80569-1.

9. Grant PM, Cotter AG. Tenofovir and bone health. Curr Opin HIV AIDS 2016;11:326-32. doi: 10.1097/ COH.0000000000000248.1.

10. Grigsby IF, Pham L, Mansky LM, Gopalakrishnan R, Mansky KC. Tenofovir-associated bone density loss. Ther Clin Risk Manag 2010;6:41-7.

11. Verhelst D, Monge M, Meynard JL, Fouqueray B, Mougenot B, Girard PM, et al. Fanconi syndrome and renal failure induced by tenofovir: a first case report. Am J Kidney Dis 2002;40:1331-3. doi: 10.1053/ ajkd.2002.36924.

12. Suh YS, Chun DI, Choi SW, Lee HW, Nho JH, Kwon $\mathrm{SH}$, et al. Pathologic femoral fracture due to tenofovir-induced Fanconi syndrome in patient with chronic hepatitis B: A case report. Medicine 2017;96:e8760. doi.org/10.1097/md.0000000000008760

13. Gibson AK, Shah BM, Nambiar PH, Schafer JJ. Tenofovir Alafenamide. Ann Pharmacother 2016;50:942952. doi: 10.1177/1060028016660812. 